\title{
Enhanced of Attendance Records Technology used Geospatial Retrieval based on Crossing Number
}

\author{
https://doi.org/10.3991/ijim.v14i16.13911 \\ Bayu Utomo, Achmad Teguh Wibowo $\left.{ }^{(}\right)$, Mujib Ridwan, \\ Muhammad Andik Izzuddin \\ UIN Sunan Ampel, Surabaya, Indonesia \\ atweuinsby $\cdot$ ac.id \\ Agustinus Bimo Gumelar \\ Universitas Narotama, Surabaya, Indonesia \\ Sirajul Arifin \\ UIN Sunan Ampel, Surabaya, Indonesia
}

\begin{abstract}
Nowadays, the fingerprint scanner widely used to records attendance. However, this technology has a weakness. Much research has done to improve the attendance system by utilizing mobile technology, like usage a fingerprint smartphone and location by GPS sensor to validate user location manually. In this research, we developed an application to enhance the records attendance system with a smartphone by crossing numbers to verify user position automatically, which implemented in a mobile app. This application using the PNPOLY method for detecting the location of the user inside of the polygon area predetermined. This method is part of the crossing number algorithm for increasing $\mathrm{x}$ and fixed $\mathrm{y}$ from point $\mathrm{P}$, which $\mathrm{x}$ is latitude, and $\mathrm{y}$ is a longitude. The result of the experiment demonstrated that the percentage of successful validate user coordinate inside edges of the polygon boundary is $83 \%$, depending on the GPS sensor embedded into a mobile device.
\end{abstract}

Keywords - Attendance system, crossing number, geospatial retrieval, mobile fingerprint, PNPOLY.

\section{Introduction}

The fingerprint scanner is one of the attendance records technology that has widely used. This technology uses an employee's fingerprint identity to authenticate the attendance process [1]. So that the technology could be a reduced wastage of paper resources, improved efficiency, security, and enhanced trusted by data, thus human error and possibly manipulated data by a human could be avoided [2].

At present, a new method for records attendance still developed. Much research has extended by an attendance system with mobile technology based on Global Positioning 
System (GPS). The result of the study says that the new method could improve accuracy from the attendance system [1].

Geographic Information System (GIS) contains much spatial data that can only be retrieved by geospatial retrieval methods [3]. GPS is one of the technologies that can retrieves data from GIS for a showing of user's locations with digital cartographic. So GPS can be tracking a user location in real-time [4]. However, GPS may not be used in some environments, such as tunnels, forests, and tall buildings [5].

Smartphone devices have become a part of every person in recent years, and almost everyone uses this device to help daily activity [6]. Now, many smartphones have a fingerprint sensor for biometric authentication, such as unlocking the smartphone and activating device security-critical functionality [7]. The combination of mobile technology, GPS, and geospatial retrieval could be utilized enhanced recording the attendance system. Mobility needed in this system to avoid queues in the fingerprint machine [1]. This system supported the trends of Bring Your Own Device (BYOD) to help work, also as an attendance device system for employees [8].

This research introduces a new method of attendance system using smartphone fingerprint and geospatial retrieval. User coordinates will be validated by spatial data from a polygon area predetermine. To determine the coordinate inside a polygon uses a Point Inclusion in Polygon Test (PNPOLY) method [9]. This method is a part of the crossing number algorithm that uses ray lines in determining the point value for the detection of location a user [10].

If coordinates of the user inside a polygon location, then the user can do scan fingerprint to the attendance system process else the user can not trigger to fingerprint authentication. Furthermore, sending data to the server use the application in the form of data of device id and location coordinates of the users.

Restriction of the developed application used the concept of Security Information and Event Management (SIEM) [11] that can be used only inside on polygon predetermined and could not use a mock location app. So that application is security guaranteed to a fake location by a user.

Back to the paper: in section 2, we show the research that is related, section 3, shows the method of attendance system using geospatial retrieval based on the PNPOLY, section 4 shows the results and section 5 shows the evaluation of this experiment, the discussion and the conclusion given in section 6 and 7 respectively.

\section{Related Work}

Their much research had been done to improve the smartphone-based attendance data collection system $[1,9,10]$. Many of them discuss the attendance system by mobile fingerprint used location GPS. User coordinates sent to the server as attendance proofed [14]. However, this system needed an administrator to check the location that sent are inside an area predetermined. The research could send the result of attendance through SMS to the smartphone device of a user application [15]. 
Other studies used a local connection to validate the user [2]. Attendance system by smartphone fingerprint activated when the user connected to the local wi-fi. The attendance system area covers coverages radius of Wi-Fi connection. Other than that, the research about the attendance system using local Wi-Fi could be used to vigilance attendance system by fusion of wireless network and biometric fingerprint authentication [16]. The result of the study conducted monitoring performance employees with validated real-time position when connected to the local Wi-Fi.

Furthermore, research about mobile-based attendance system using QR code [17]. That study developed an application for lecturer and student. The lecturer could generate QR code for records attendance students with a mobile app in the classroom, this research using Android technology for front-end and PHP to the back-end.

The next study developed an application to records attendance systems using Bluetooth Low Energy (BLE) technology [18]. The application analyzed every device that attached each other with an infrared motion analyzer to count the number of students that entering into the classroom [19].

Based on this research of the smartphone-based attendance system, this study to be inspired to develop the application with point inclusion method to validate the user is inside a polygon area that predetermined. So that developed application has been made could be enhanced attendance system and advantage usage of a mobile device such as run in everywhere and anytime.

\section{Inclusion of a Point in a Polygon}

\subsection{Geospatial retrieval}

This research used polygon coordinates of Islamic State University of Sunan Ampel Surabaya taken from OpenStreetMap service [20]. The mapping used a react-nativemap library [11,12], and the process used Google API Service [23] to develop an application. That map displayed the polygon area of an object region to enhanced of attendance system based on geospatial retrieval [24].

\subsection{Crossing number}

A crossing number is a method to determine a point inside a polygon. This method was counting ray lines crossing the polygon of boundary edges from point P. If the crossing number is even, then the point is outside a polygon area else, the crossing number is odd, then the value is inside a polygon area [10]. 


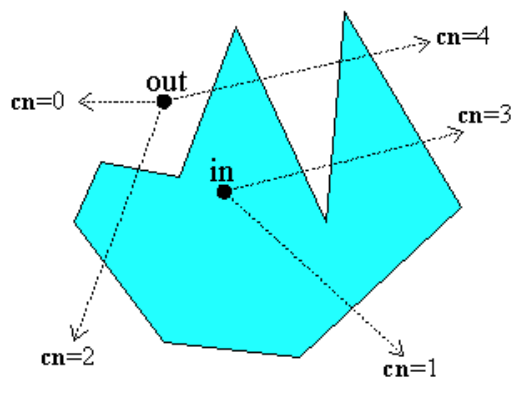

Fig. 1. Crossing number algoritm [10]

The movement of the inside or outside in the crossing number method is base on the Jordan Curve Theorem [10]. That theorem says a line repetition that does not intersect an object, separated into two components [25]. Equation this theorem showed in below.

$$
C=\left\{(x, y) ; x^{2}+y^{2}=1\right\}
$$

Where:

$\mathrm{C}=$ Curve Theorem

$\mathrm{x}, \mathrm{y}=$ the points of coordinated tested

\subsection{PNPOLY}

PNPOLY is a development method from a ray casting algorithm. This algorithm is a part of the crossing number method. The PNPOLY runs a semi-infinite ray horizontal (increasing $\mathrm{x}$, fixed $\mathrm{y}$ ) from point $\mathrm{P}$, and counting many boundary edges it crosses. An equation a PNPOLY method explained below.

$$
n \sum_{y=0}^{m} y\left(x_{n}-x_{m}\right)-m \sum_{y=0}^{n} x\left(y_{n}-y_{m}\right)>n m\left(x_{n} y_{m}+x_{m} y_{n}\right)
$$

Where $\mathrm{n}$ is a point of ray crossed polygon boundary, and $\mathrm{m}$ is a point of the edge of a polygon. Then, symbol $\mathrm{x}$ and $\mathrm{y}$ tested point. The pseudocode of this method shows below.

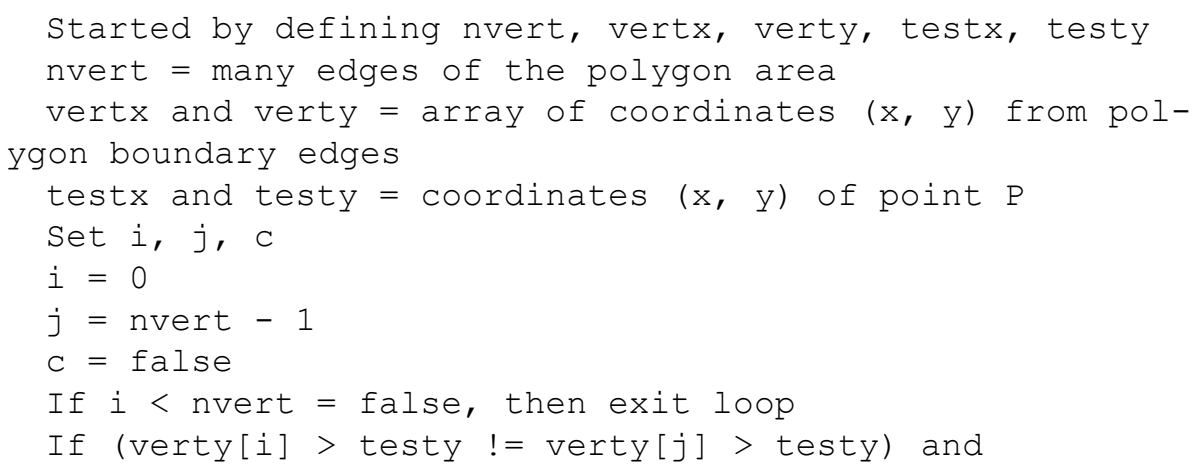




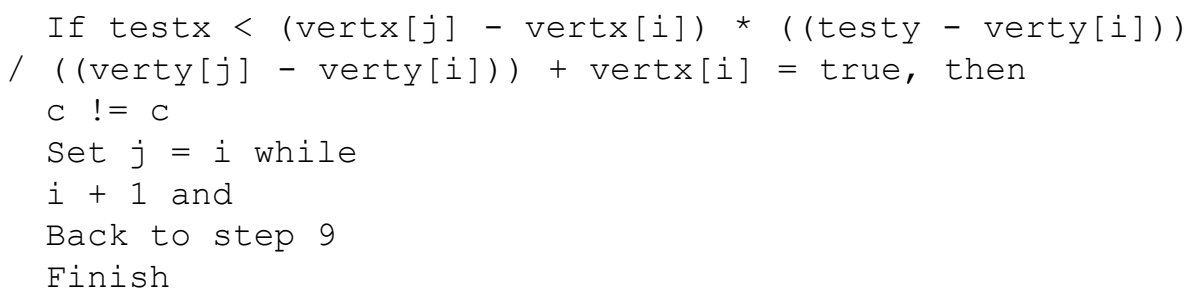

\section{Design and Implementation}

\subsection{Design system}

We implemented the PNPOLY method that integrated with the mobile app has developed. This application could run in a smartphone device that has a fingerprint sensor with Android or IOS. Fig. 2 illustrates the design architecture of the proposed application consists of a recommender server, client, and validated method. The recommender server divided into three-layer. First, the API layer to perform a convert of raw data to a JSON array. The next is the application layer that executes a query to databases from each function, and the last layer database used to store data of the attendance system.

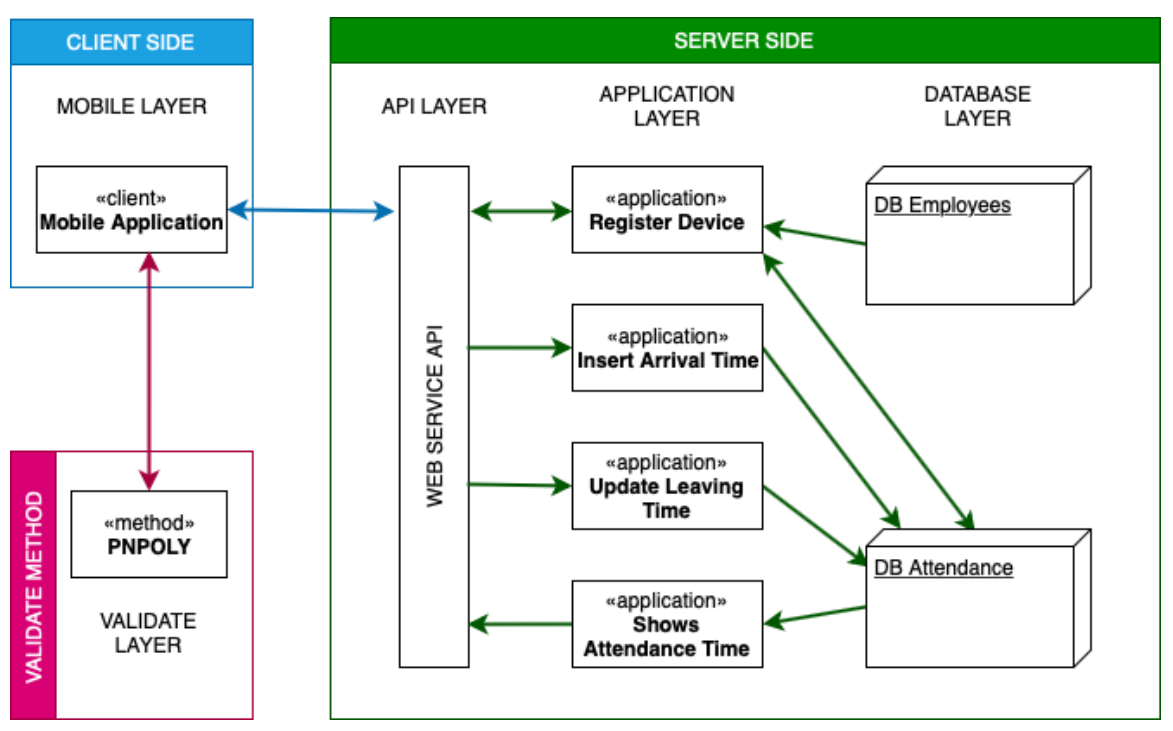

Fig. 2. Design architecture of a proposed application

The mobile layer in the client area used to perform records attendance on the clientside by a fingerprint scanner, retrieved data sent to the database via the API and application layer, respectively. Before the fingerprint function is activated, the user 
real-time location validated with the PNPOLY method from a validated layer. Fig. 3 shows workflows of the application that proposed.

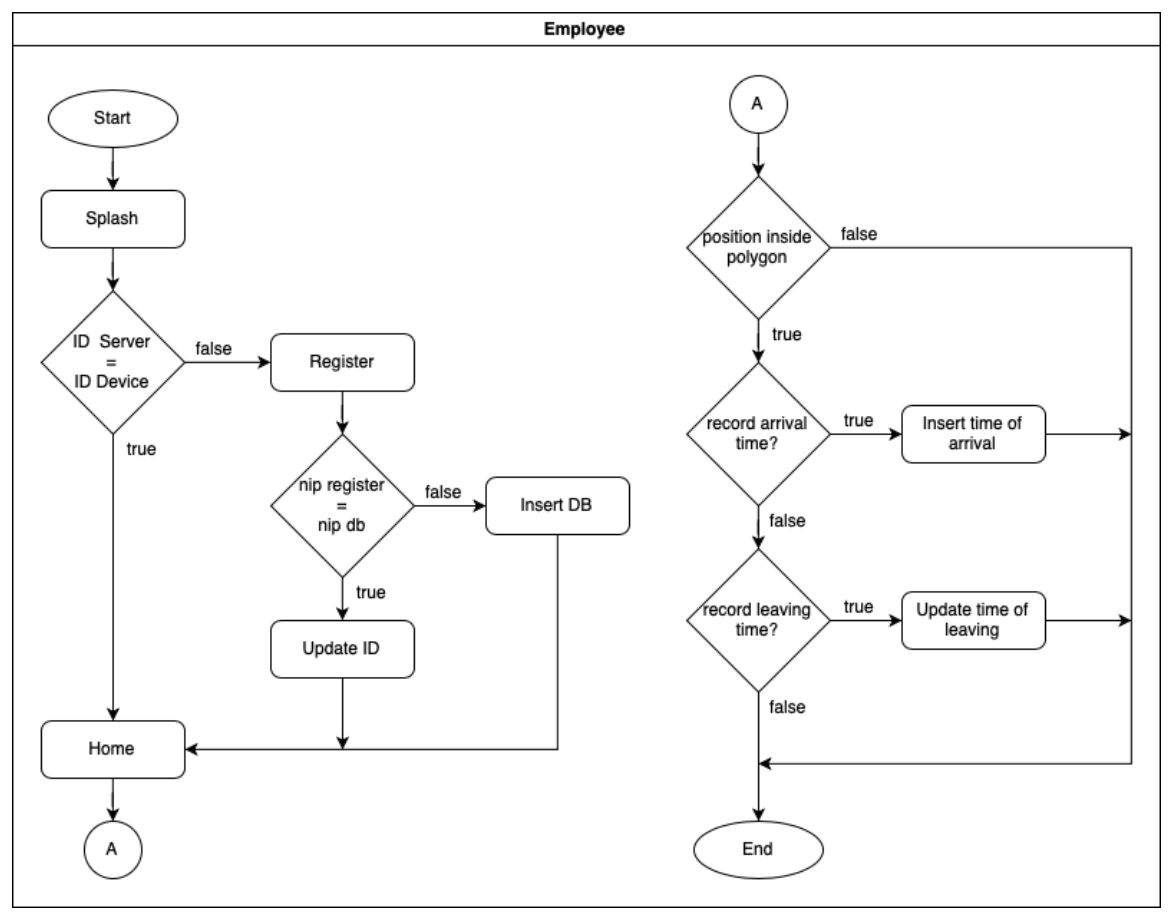

Fig. 3. Workflows of a proposed application

The design of detailed workflow used Undefined Modeling Language (UML) sequence and class diagram. Sequence diagrams divided into three sections. The registered device diagram inserts arrival time diagram and update the return time diagram. That flow of the first sequence diagram starts from the process checking device id on the splash screen. If resulted false, then the screen would redirect to register device form. Furthermore, the user could access a home screen. The sequence diagram of the registered device shown in Fig. 4. 


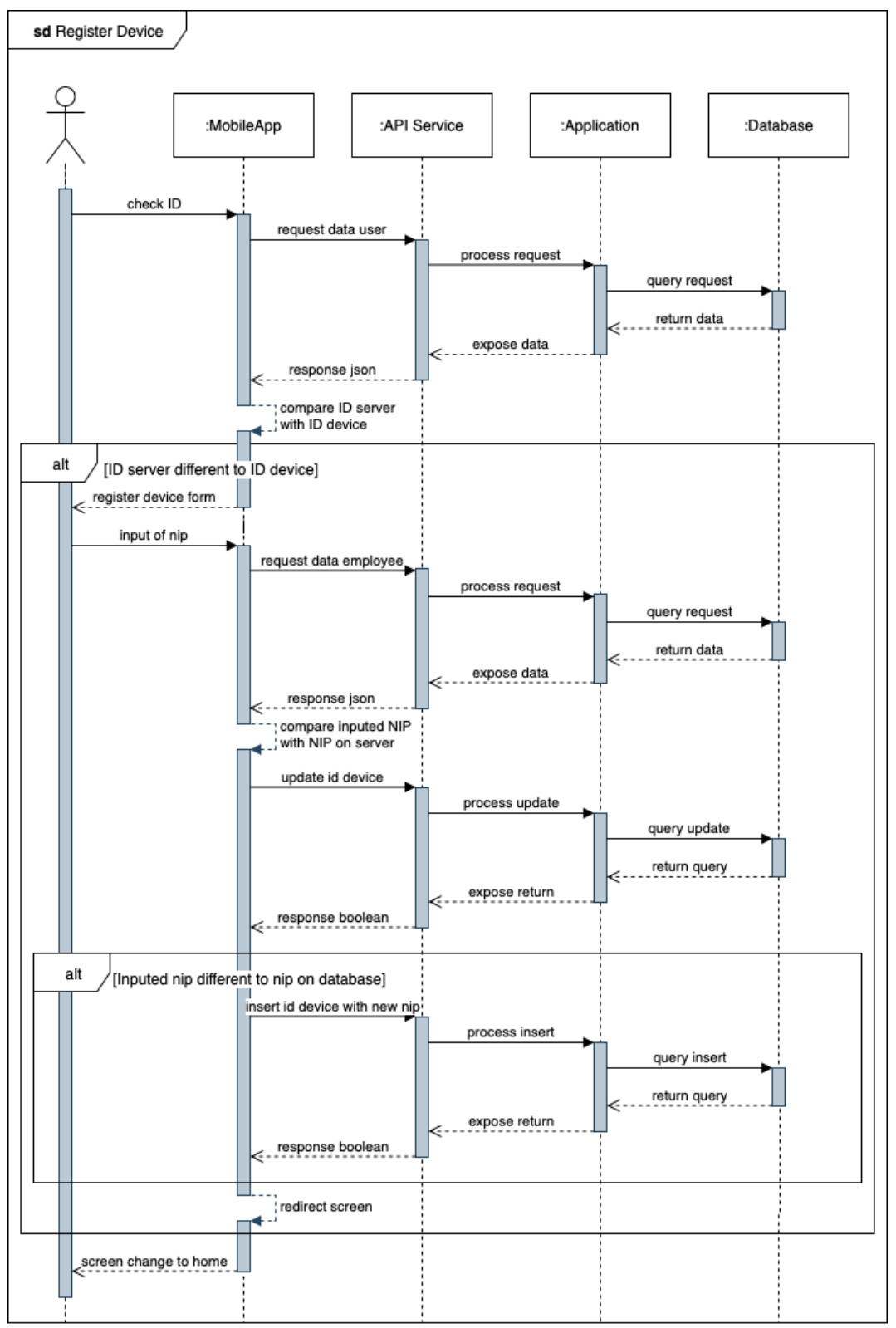

Fig. 4. Sequence diagram of the register device

The validation method would determine position users when the home screen of the application is open. Flows of the second sequence diagram start after these result true and fingerprint scanner used by a user. Then, user attendance data sent to the database server. Fig. 5 illustrated the sequence diagram of insert arrival time. The third sequence used the same flows but used different queries that show in Fig. 6. 


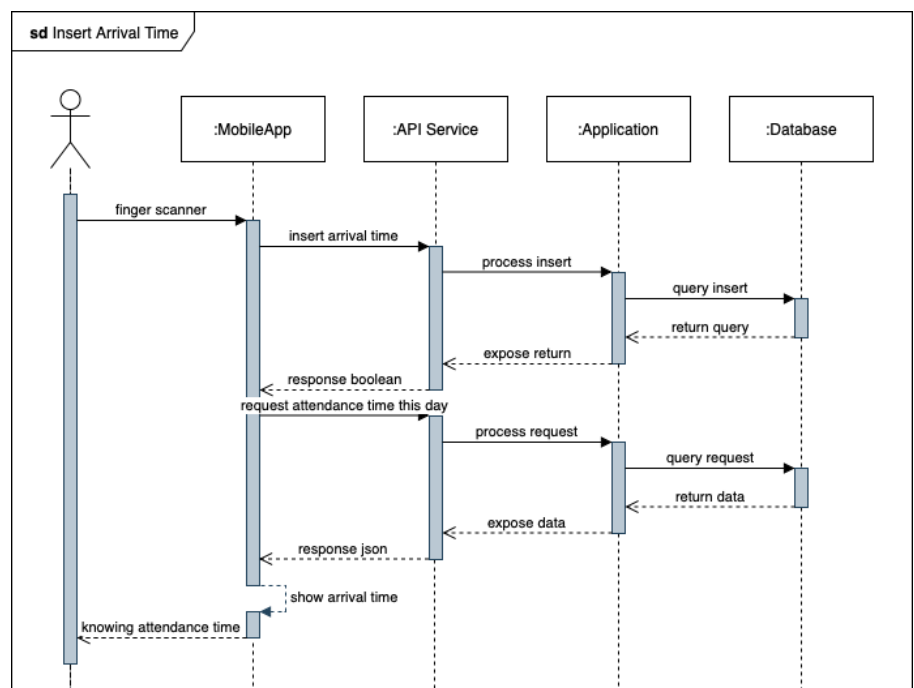

Fig. 5. Sequence diagram of the insert arrival time

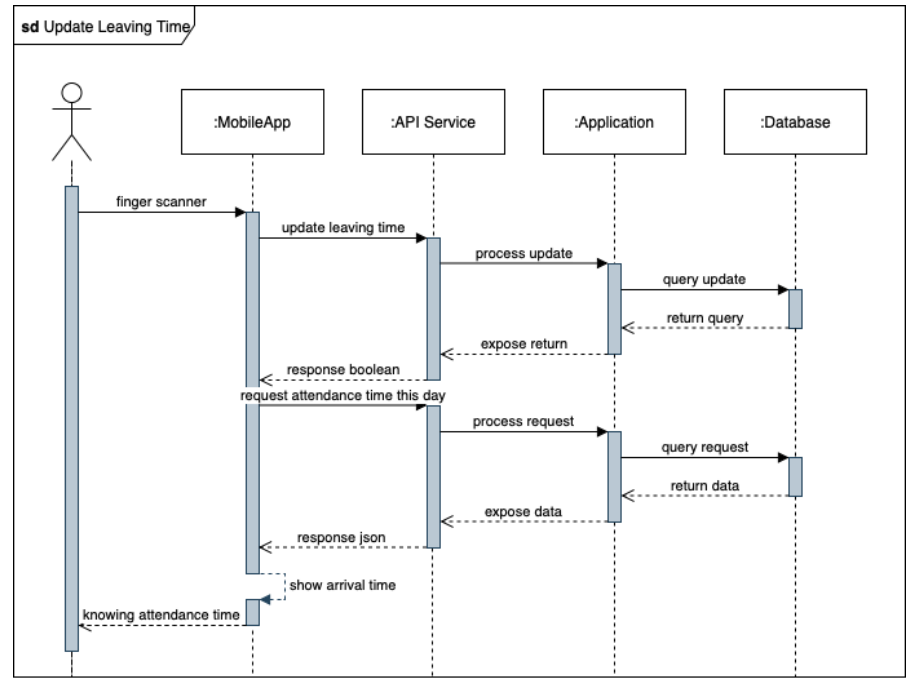

Fig. 6. Sequence diagram of the update return time

This system has nine class diagram that divides into two sections. Four class (User, NIP, FetchAPI, DeviceID) in frontend section and five class (QueryEmployee, ControllerNIP, QueryAttendance, ControllerUser, ControllerAttendance) in backend section. FetchAPI is the main class of this application witch control all function in fronted and makes request API to the backend. Fig. 7 sown class diagram for the proposed application. 


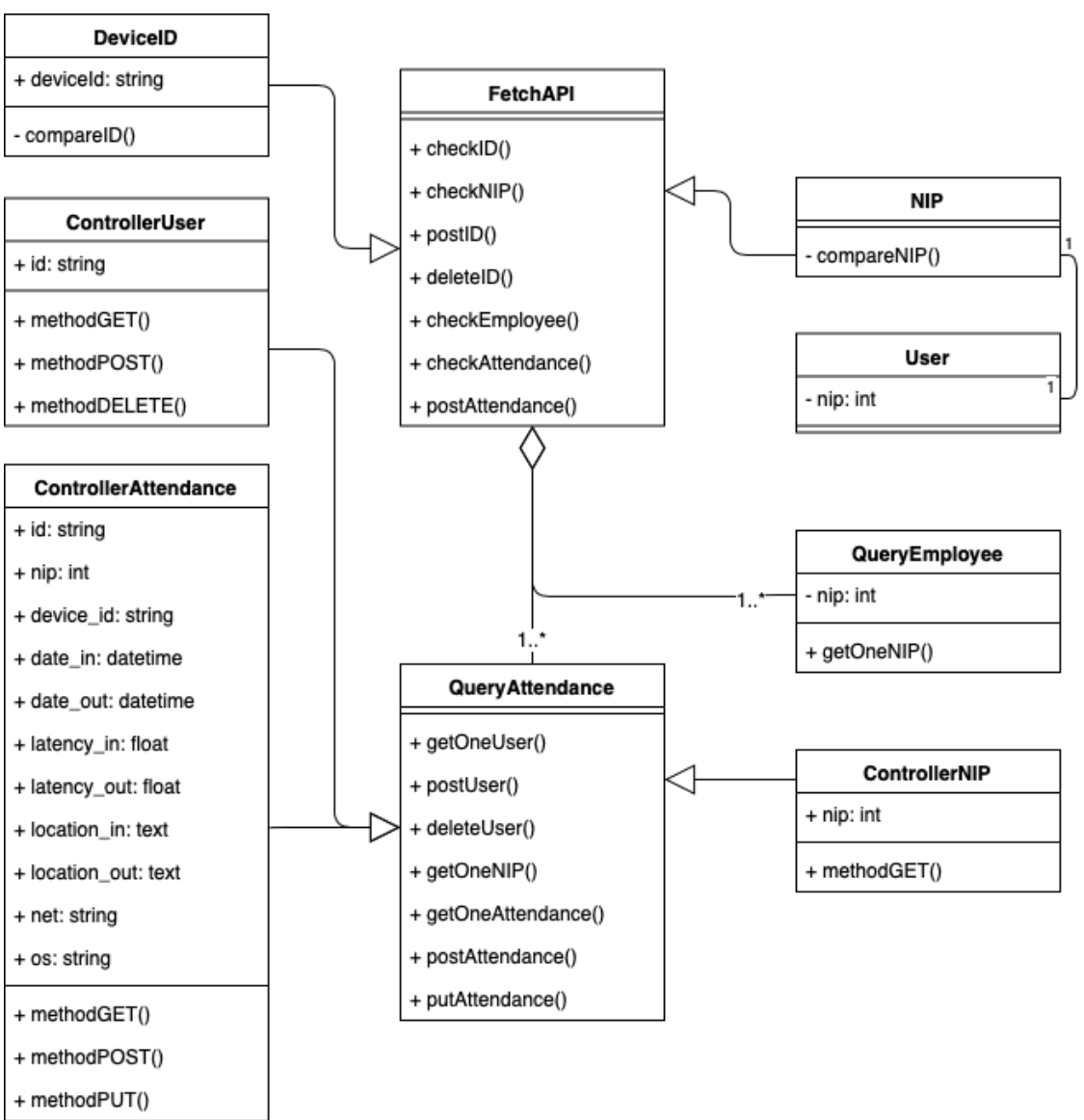

Fig. 7. Class diagram of the proposed application

\subsection{Coordinates validation}

The proposed application needed an active GPS sensor to retrieve coordinates position (latitude and longitude) when it runs by a user. These coordinates used to validate user position from a predetermined polygon area with the PNPOLY method. The validation processed every time the user position changed. Fig. 8 illustrated screens of an application when the user position is different. 


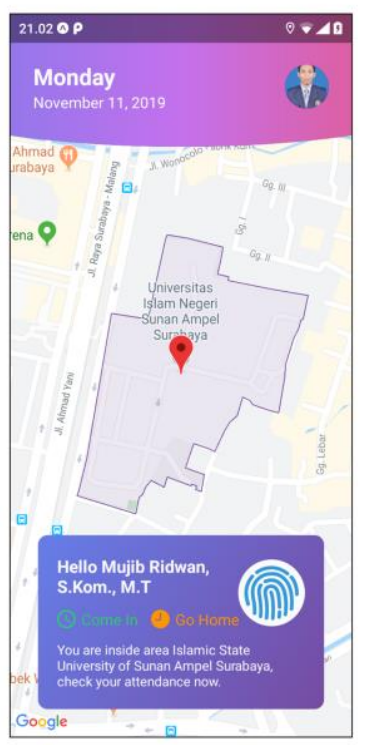

a) Screenshot of a mobile app with the condition inside a polygon area

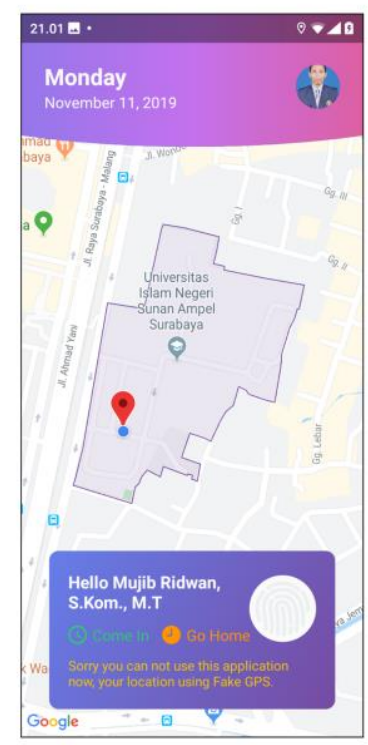

b) Screenshot of a mobile app with a mock location from Fake GPS

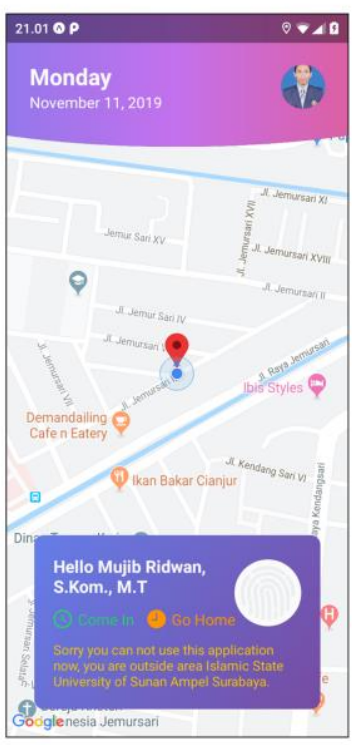

c) Screenshot of a mobile app with the condition outside of the polygon area

Fig. 8.

The records attendance feature activated when the PNPOLY method indicates user coordinates are on inside a polygon. This application used fake location detection to restricted user usage. So the user can not use a mock location app and only can usage this application inside of the area that predetermined. Users could record attendance used fingerprint id in the device.

\section{$5 \quad$ Testing}

In this section, we tested a developed application by evaluating the PNPOLY implementation method and tested the effect of the cellular network. The first testing used 48 data coordinates inside edges of the polygon boundary, which has specified. The next experiment used four operating systems and three network cellular categories that tested 100 times by each network. 


\subsection{Evaluate PNPOLY implementation}

The percentage of successful PNPOLY methods implemented in this application showed in Table 1. We expected 48 data successfully tested, but in fact, 8 data failed to check. That resulted in a $17 \%$ margin error in the test because of the different accuracy of the GPS sensor embedded into a mobile device. So, lowers margin error affected by higher GPS accuracy.

Table 1. The percentage of successful PNPOLY method

\begin{tabular}{|l|c|c|}
\hline & Expectation & Fact \\
\hline Success & 48 & 40 \\
\hline Failed & 0 & 8 \\
\hline Total & 48 & 48 \\
\hline Percentage of success & $100 \%$ & $83 \%$ \\
\hline Percentage of failed & $0 \%$ & $17 \%$ \\
\hline
\end{tabular}

\subsection{Effect of cellular network}

In the next of experiments, we showed the effect of the cellular network on the application. The operating systems used for the testing divide to Android versions ( 8 and 9) and IOS versions (11 and 12). The Android operating system tested by three category networks ( $2 \mathrm{G}, 3 \mathrm{G}$, and $4 \mathrm{G}$ ), but on IOS, only two network categories ( $3 \mathrm{G}$ and $4 \mathrm{G})$ because of IOS architecture restrict applications that run on $2 \mathrm{G}$ network. The experiment resulted in network latency that shows in Fig. 9.
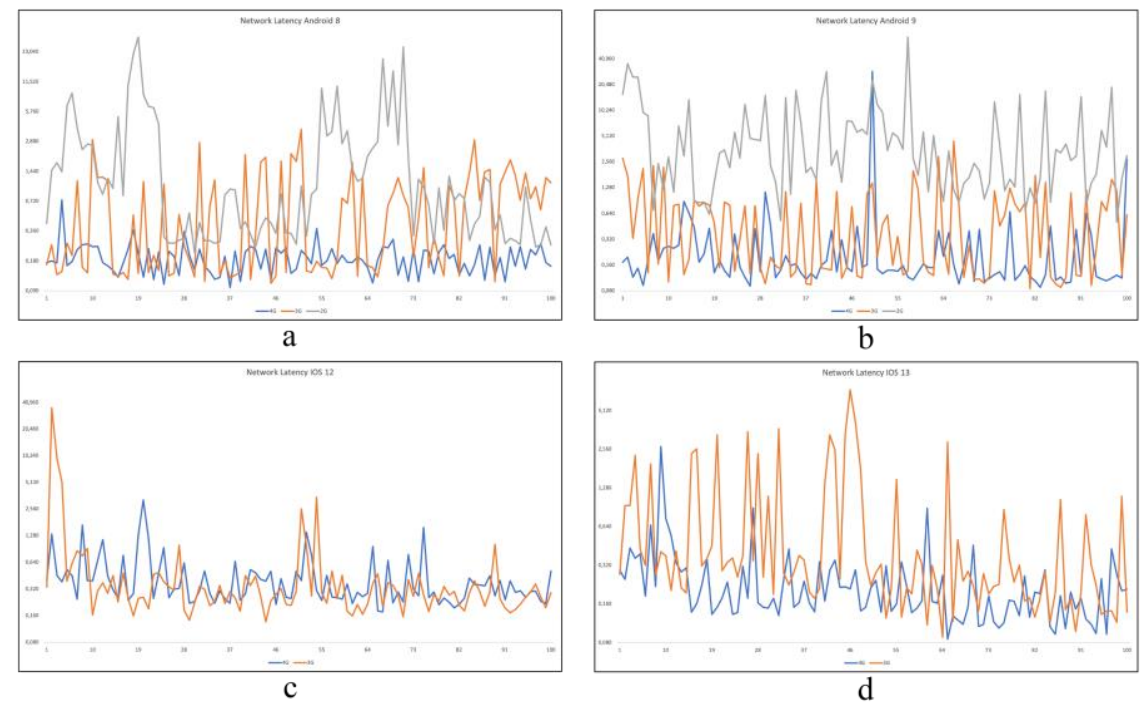

Fig. 9. (a) The network latency when using an application on Android 8. (b) The network latency on Android 9. (c) The network latency on IOS 12. (d) The network latency on

IOS 13 
Furthermore, we calculated the average network latency in each operating system then compared. The result of the comparison shown in Fig 10.

Table 2. The average of network latency

\begin{tabular}{|c|c|c|c|c|}
\hline & Android 8 & Android 9 & IOS 12 & IOS 13 \\
\hline $2 \mathrm{G}$ & 2.776 & 6.459 & & \\
\hline $3 \mathrm{G}$ & 0.732 & 0.657 & 0.875 & 0.761 \\
\hline $4 \mathrm{G}$ & 0.198 & 0.533 & 0.461 & 0.254 \\
\hline
\end{tabular}

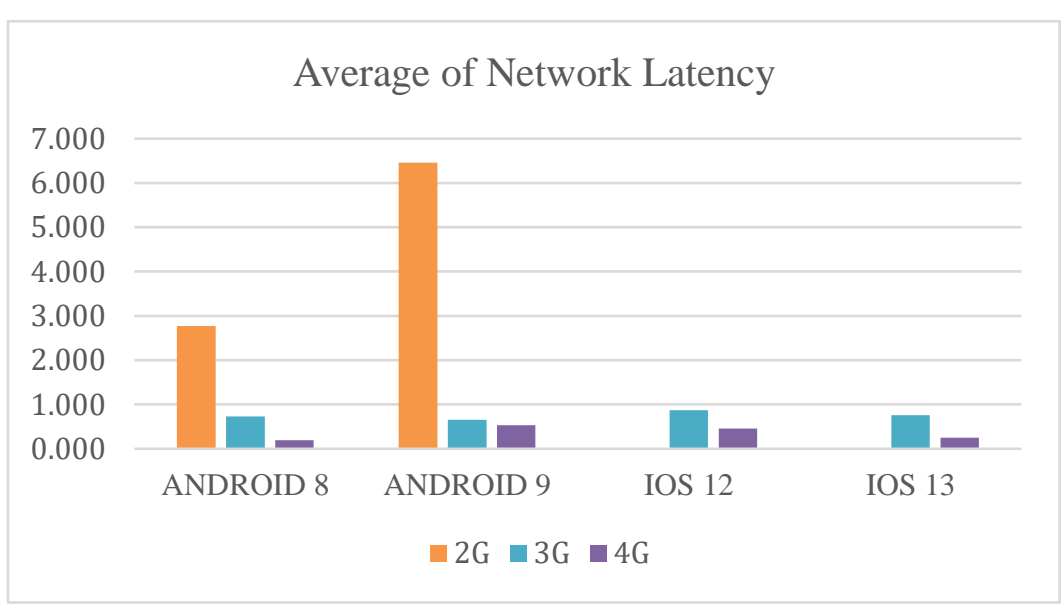

Fig. 10.The average of network latency while using the application

Fig 10 explained the average network latency while using the application. The result of the 4G connection on Android 8 gets the smallest latency network compared to others. The operating system that tested shows network latency in $3 \mathrm{G}$ connection, a slight difference from each other, and the $2 \mathrm{G}$ network resulted in the large latencies. The result of the latency Android 8 (Oreo) recorded average amounts of 2.776s, and Android 9 (Pie) amounts to 6.459s. However, IOS 12 and IOS 13 could not run in this network.

\section{Discussion}

Enhance of attendance records technology used geospatial retrieval based on crossing number is not only restricted to usage fingerprint ID but also can use other biometric ID on mobile, such as face ID, voice recognition or iris ID [26].

The implement of crossing numbers not only applied to the attendance system but also applied for surveillance technology using Unmanned Aerial Vehicles (UAVs), based on the polygon area predetermined. This technology combined with IoT for various services such as military, smart city, agriculture, and many more [27]. Other than that, the advantage of this combined technology could implement for agriculture technology to extends the product of agriculture based on geospatial retrieval [28]. 
Furthermore, PNPOLY can implement use a winding number algorithm [29]. This algorithm does it possible to enhance for validated the location of the user on each building inside of the main polygon. However, this method suitable for usage in a large area that has many buildings inside of the polygon. The combining of winding number algorithm and IoT can implement to detect an object that enters dangerous polygon area predetermined, such as mine suspect area [30].

The security development of data in the application can integrate with blockchain technology. Because this technology emphasize security with cryptography and smart contracts for all transaction depend on the method to the consensus that used. Other than that, blockchain technology supported a decentralized database, so challenging to change the data into the ledger.

\section{Conclusion}

The records attendance system using a smartphone fingerprint is a solution to reduce the weakness of the conventional fingerprint machine. A combination of the fingerprint with a GPS sensor of the smartphone could track to the attended user location like previous research.

The goal in this study to enhance attendance records technology using geospatial retrieval based on the crossing number algorithm for automatically detected the live location of the user inside or outside the polygon area predetermined. This research developed applications using the mobile app because this technology could be used anywhere and anytime. The experiment results from the evaluation of around the polygon boundary are work, and margin of errors of $17 \%$ depending on the accuracy of the GPS sensor embedded to a mobile device.

We suggested to use an application with a $4 \mathrm{G}$ connection on Android 8 because the result of the experiment has done, showed this operating system has the smallest average latency of all network. Furthermore, we not recommended used this application on the $2 \mathrm{G}$ network, especially IOS; see Table 2 and edges of the polygon boundary predetermined because the determine of user location utilizes the accuracy of the GPS sensor.

\section{$8 \quad$ References}

[1] B. Soewito, F. L. Gaol, E. Simanjuntak, and F. E. Gunawan, "Attendance system on Android smartphone," ICCEREC 2015 - Int. Conf. Control. Electron. Renew. Energy Commun., pp. 208-211, 2015. https://doi.org/10.1109/ICCEREC.2015.7337046

[2] S. S., V. D., and S. Waghmare, "Remote Biometric Authentication System using Android Phone," Int. J. Comput. Appl., vol. 180, no. 33, pp. 6-12, 2018. https://doi.org/10.5120 lijca2018916811

[3] R. S. Purves, P. Clough, C. B. Jones, M. H. Hall, and V. Murdock, "Geographic information retrieval: Progress and challenges in spatial search of text," Found. Trends Inf. Retr., vol. 12, no. 2-3, pp. 164-318, 2018. https://doi.org/10.1561/1500000034 
[4] L. E. Wood, "Locating People, Places, and Things: Situating GIS in the Intelligent Network Landscape," Glob. Media J., vol. 10, no. 19, pp. 1-11, 2011.

[5] Y. Zhang, "A Fusion Methodology to Bridge GPS Outages for INS/GPS Integrated Navigation System," IEEE Access, vol. 7, pp. 61296-61306, 2019. https://doi.org/10.1109 /ACCESS.2019.2911025

[6] H. M. azer Al Fawareh and S. Jusoh, "The use and effects of smartphones in higher education," Int. J. Interact. Mob. Technol., vol. 11, no. 6, pp. 103-111, 2017. https://doi.org/10.3991/ijim.v11i6.7453

[7] Y. H. Jo, S. Y. Jeon, J. H. Im, and M. K. Lee, "Security analysis and improvement of fingerprint authentication for smartphones," Mob. Inf. Syst., vol. 2016, no. Krait 400, 2016. https://doi.org/10.1155/2016/8973828

[8] S. B. Utomo and B. Hendradjaya, "Multifactor Authentication on Mobile Secure Attendance System," Proceeding - 2018 Int. Conf. ICT Smart Soc. Innov. Towar. Smart Soc. Soc. 5.0, ICISS 2018, 2018. https://doi.org/10.1109/ICTSS.2018.8550017

[9] W. R. Franklin, "PNPOLY - Point Inclusion in Polygon Test - WR Franklin (WRF)," 2006. [Online]. Available: http://www.ecse.rpi.edu/Homepages/wrf/Research/Short_Notes/pnpoly.html.

[10] D. Sunday, "Inclusion of a Point in a Polygon," http://geomalgorithms.com, 2012. [Online]. Available: http://geomalgorithms.com/a03-_inclusion.html.

[11] M. Schölzel, E. Eren, K. O. Detken, and L. Schwenke, "Monitoring android devices by using events and metadata," Int. J. Comput., vol. 15, no. 4, pp. 248-258, 2016.

[12] P. Wadhwa, "Attendance System Using Android integrated Biometric Fingerprint Recognition," Int. Res. J. Eng. Technol., vol. 4, no. 6, pp. 1069-1073, 2017.

[13] S. Sultana, A. Enayet, and I. J. Mouri, "A Smart, Location Based Time and Attendance Tracking System using Android Application," Int. J. Comput. Sci. Eng. Inf. Technol., vol. 5, no. 1, pp. 01-05, 2015. https://doi.org/10.5121/ijcseit.2015.5101

[14] M. Y. Khan, "GPS Enabled Employee Registration and Attendance Tr acking System," pp. 62-65, 2015.

[15] L. Kamelia, E. A. D. Hamidi, W. Darmalaksana, and A. Nugraha, "Real-Time Online Attendance System Based on Fingerprint and GPS in the Smartphone," Proceeding 2018 4th Int. Conf. Wirel. Telemat. ICWT 2018, 2018. https://doi.org/10.1109/ICWT.2018.8527837

[16] H. Adal, N. Promy, S. Srabanti, and M. Rahman, "Android based advanced attendance vigilance system using wireless network with fusion of bio-metric fingerprint authentication," Int. Conf. Adv. Commun. Technol. ICACT, vol. 2018-Febru, pp. 217-222, 2018. https://doi.org/10.23919/ICACT.2018.8323701

[17] H. Abdelhafez, M. Alamri, R. Alomari, B. Alzoman, R. Binsheeha, and A. Albawardi, "Mobile Based Attendance System Using QR Code," vol. 9, no. 4, pp. 17-21, 2019.

[18] S. Noguchi, M. Niibori, E. Zhou, and M. Kamada, "Student attendance management system with bluetooth low energy beacon and android devices," Proc. - 2015 18th Int. Conf. Network-Based Inf. Syst. NBiS 2015, pp. 710-713, 2015. https://doi.org/10.1109 /NBiS.2015.109

[19] R. Apoorv and P. Mathur, "Smart attendance management using Bluetooth Low Energy and Android," IEEE Reg. 10 Annu. Int. Conf. Proceedings/TENCON, pp. 1048-1052, 2017. https://doi.org/10.1109/TENCON.2016.7848166

[20] OpenStreetMap Foundation, "OpenStreetMap," 2019. [Online]. Available: https://www. openstreetmap.org/way/470103964.

[21] Facebook Inc, "React Native," 2019. [Online]. Available: https://facebook.github.io/reactnative/docs/getting-started 
[22] Airbnb, "React Native Map," 2017. [Online]. Available: https://github.com/react-nativecommunity/react-native-maps

[23] Google Inc, "Google Map API," 2019. [Online]. Available: https://developers.google.com/maps/documentation.

[24] C. B. Jones and R. S. Purves, "Geographical information retrieval," Int. J. Geogr. Inf. Sci., vol. 22, no. 3, pp. 219-228, 2008. https://doi.org/10.1080/13658810701626343

[25] F. Ross and W. T. Ross, "The Jordan curve theorem is non-trivial," J. Math. Arts, vol. 5, no. 4, pp. 213-219, 2011. https://doi.org/10.1080/17513472.2011.634320

[26] B. Soewito, F. E. Gunawan, and M. Hapsara, "Smartphone for next generation attendance system and human resources payroll system," Int. Conf. Electr. Eng. Comput. Sci. Informatics, vol. 4, no. September, pp. 313-318, 2017. https://doi.org/10.1109/EECSI.2017.8239130

[27] J. H. Park, S. C. Choi, I. Y. Ahn, and J. Kim, "Multiple UAVs-based surveillance and reconnaissance system utilizing IoT platform," ICEIC 2019 - Int. Conf. Electron. Information, Commun., pp. 1-3, 2019. https://doi.org/10.23919/ELINFOCOM.2019.8706406

[28] W. Han, Z. Yang, L. Di, B. Zhang, and C. Peng, "Enhancing agricultural geospatial data dissemination and applications using geospatial web services," IEEE J. Sel. Top. Appl. Earth Obs. Remote Sens., vol. 7, no. 11, pp. 4539-4547, 2014. https://doi.org/10.1109/ JSTARS.2014.2315593

[29] G. N. Kumar and M. Bangi, "An Extension to Winding Number and Point-in-Polygon Algorithm," IFAC-PapersOnLine, 2018. https://doi.org/10.1016/j.ifacol.2018.05.092

[30] T. Baroš and T. Stojanović, "Geographic Information System (GIS) in Mapping of Mine Suspected Area in the Republic of Serpska," Glob. J. Sci. Front. Res. H Environ. Earth Sci., vol. 15 , no. 3, pp. 0-4, 2015.

\section{Authors}

Bayu Utomo is a bachelor's degree from the Islamic State University of Sunan Ampel Surabaya, Indonesia. His current interests in Computer Science and Technology with a concentrate on Mobile Computing.

Achmad Teguh Wibowo received a bachelor's degree in Information systems from STIKOM, Surabaya, Indonesia, in 2010. He received his Master of Electrical Engineering from Brawijaya University, Malang, Indonesia in 2013. He joined the Information System Department as a lecturer at the Islamic State University of Sunan Ampel, Surabaya. Indonesia since 2014. His current interests are Blockchain, and Intelligent System. He is currently pursuing a Ph.D. degree at Institut Teknologi Sepuluh Nopember (ITS), Surabaya, Indonesia, since 2019.

Mujib Ridwan received a bachelor's degree in Information Technology from Islamic State University of Maulana Malik Ibrahim, Malang, Indonesia, in 2009. He received his Master of Electrical Engineering from Brawijaya University, Malang, Indonesia in 2013. He joined the Information System Department as a lecturer at the Islamic State University of Sunan Ampel, Surabaya. Indonesia since 2014. His current interest in Data Mining and Deep Learning.

Muhammad Andik Izzuddin received a bachelor's degree in Information and Technology Education from Universitas Negeri Malang (UM), Malang, Indonesia in 2011. He received his Master of Electrical Engineering from Institute of Technology Bandung (ITC), Bandung, Indonesia in 2013. He joined the Information System Department as 
a lecturer at the Islamic State University of Sunan Ampel, Surabaya. Indonesia since 2014. His current interests are Computer Networks, and Internet of Things.

Agustinus Bimo Gumelar received the Bachelor's degree in Industrial Engineering from Institut Teknologi Sepuluh Nopember (ITS), Surabaya, Indonesia, in 2004 and the Master Degree in Electrical Engineering from Institut Teknologi Sepuluh Nopember (ITS), Surabaya, Indonesia in 2010 with Honour. In 2019, He is currently working toward the Ph.D. degree in Electrical Engineering at Institut Teknologi Sepuluh Nopember (ITS), Surabaya, Indonesia. He is a lecture in the Faculty of Computer Science at the Narotama University, Surabaya, Indonesia. His research interests include auditorybased neuroscience and affective computing, signal processing, and computational intelligence.

Sirajul Arifin is an Associate Professor in the Faculty of Islamic Economics and Business UIN Sunan Ampel Surabaya. He completed both bachelor's degrees at IAI Ibrahimy Situbondo and the University of Indonesia Jakarta. The first degree is in Islamic Economic Law, whereas the second is Information Sciences. In 2002 he obtained a Master of Islamic Economics from IAIN Sunan Ampel Surabaya. Six years later he pursued a Ph.D. degree in Islamic Economics at UIN Sunan Kalijaga Yogyakarta and completed in 2014. Now he serves as Vice Dean for Academic and Institutional Affairs at the Faculty of Islamic Economics and Business UIN Sunan Ampel Surabaya.

Article submitted 2020-02-24. Resubmitted 2020-07-11. Final acceptance 2020-07-12. Final version published as submitted by the authors. 